\title{
Yaşlı Bireylerde Üst Ekstremite Fonksiyonları ile Denge Arasındaki İlişkinin İncelenmesi
}

\author{
Investigation of the Relationship Between Upper Extremity Functionsand Balance \\ in Elderly Individuals
}

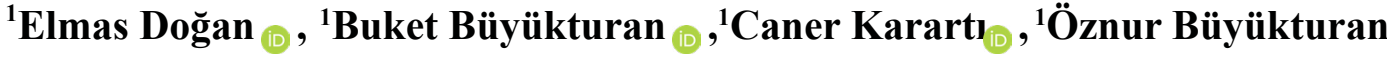

\footnotetext{
Kırșehir Ahi Evran Üniversitesi, Fizik Tedavi ve Rehabilitasyon Yüksekokulu, Kırşehir, Türkiye
}

\begin{abstract}
Özet
Yaşlı bireylerde üst ekstremite fonksiyonlarını ve dengeyi ayrı ayrı inceleyen birçok çalışma bulunmasına rağmen, üst ekstremite fonksiyonları ile denge arasındaki ilişkiyi inceleyen çalışmaların yetersiz olduğu tespit edilmiştir. Bu çalışmanın amacı yaşlı bireylerde üst ekstremite fonksiyonları ile denge arasındaki ilişkiyi incelemektir. Bu çalışmaya yaşları 65 ve üzeri olan 80 yaşlı birey dahil edilmiștir. Bireylerin üst ekstremite fonksiyonlarını değerlendirmek için Jamar El Dinamometresi, 9 Delikli Peg Testi ve purduepeg board testi kullanılmıştır. Bireylerin dengelerini değerlendirmek için Berg Denge Ölçeği, Tinetti Denge ve Yürüme Testi, Biodex Denge Sistemi ve Tek Ayak Üzerinde Durma Testi kullanılmıştır. Bireylerin Jamar El Dinamometresi, 9 Delikli Peg Testi ve purduepeg board testi ile Berg Denge Ölçeği, Tinetti Denge ve Yürüme Testi, Biodex Denge Sistemi ve Tek Ayak Üzerinde Durma Testi aralarında anlamlı ilişki bulunmuştur $(\mathrm{p}<0,05)$. Bu çalışmanın sonunda üst ekstremite fonksiyonları ile denge arasında ilişki olduğu tespit edilmiştir. Yaşlı bireylerde üst ekstremite fonksiyonları ile ilgili kavrama kuvvetini, el becerilerini arttıran yaklaşımların bozulan denge ve buna bağlı günlük yaşam aktivitelerinde yaşanan sorunlar için yararlı olacağını düşünmekteyiz.
\end{abstract}

Anahtar Kelimeler: Yaşl1, denge, el fonksiyonları, yürüme

\section{Abstract}

Al though there aremany studie sex aminin gupper extremity functionsand balance separately in elderly individuals, studie sinvestigating there lationship between upper extremity functionsand balance have been found to be insufficient. Theaim of this study wastoin vestigate there lationship between upper extremity function sand balance inelderly individuals. Eighty elderly individuals aged 65 andover wereincluded this study. Upper extremity functions were evaluated by Jamar Hand Dynamometer, Nine Hole Peg Test, Purdue Pegboard Test and Jebsen Taylor Hand Function Test; balance were evaluated by Berg Balance Scale, Tinetti Balance and Gait Assessment Tool, Standing Balance on One Leg Test and Biodex Balance System. There was a signifi cant relationship between Jamar hand dynamometer, Nine Hole Peg Test and purdue peg board test, BergBalanceScale, Tinetti Balance and Walking Test, Biodex Balance System (BDS) and Standing On One Foot Test of elderly individuals $(\mathrm{p}<0.05)$. As a result of this study, it was found that there was a relationship between upper extremity function sand balance. We think that rehabilitative appro achesre gardin gupper extremity functions in elderly individuals will be ben eficial for impaired balance and related problems in daily living activities.

Keywords: Elderly, balance, handfunctions, walking

\section{Correspondence: Buket Evran Üniversitesi, Fizik Tedavi ve Rehabilitasyon Yüksekokulu, Kırşehir, Turkey. \\ e-mail:fztkaya04@hotmail.com Received: 28.04 .2020 \\ Accepted: 06.07.2020 \\ Online published: 06.07.2020}




\section{Giriş}

Üst ekstremite fonksiyonları günlük yaşam aktivitelerinde önemli bir rol oynar ve bağımsızlık ölçütünün önemli bir parçası olarak kabul edilmektedir (1). Yaşın artmasıyla birlikte meydana gelen duyu-motor algisıyla ilgili bozukluklar üst ekstremite fonksiyonlarını etkileyebilir ve bu durum yaşlı bireylerin günlük yaşam aktivitelerindeki bağımsızlıklarını kaybetmesine neden olabilmektedir (2).

Dengeyi korumak, bireylerin günlük işlerini düşmeksizin yerine getirebilmelerinde temel teşkil etmektedir (3). Yaşlanma ile dengeyi etkileyen merkezi sinir sisteminde birtakım değişikliklerin meydana gelmesiyle birçok yaşlı bireyde, bağımsız hareket kabiliyeti kısıtlanmakta ve denge kaybı görülmektedir $(4,5)$. Toplum içinde yaşayan 65-69 yaş aralığındaki bireylerin \%13'ünde, 85 yaş ve üzerindekilerin ise \%46'sından fazlasında dengenin bozulduğu yapılan çalışmalarda rapor edilmiştir (6).

Literatürde üst ekstremite fonksiyonlarını araştıran birçok çalışma bulunmaktadır. Yapılan çalışmalarda, kavrama kuvvetinde yaş ile birlikte azalmanın, kuvvet veya beceri gerektiren ya da her ikisini de gerektiren görevlerdeki fonksiyonel performansın azalmasıyla pozitif bir korelasyona sahip olduğu gösterilmiştir (7). Ayrıca, kavrama kuvveti ile diğer kas gruplarının kuvveti arasında bir ilişki olduğu, bu da kavrama kuvvetinin yaşlı insanların genel kassal performansını yansıtmak için güvenilir bir parametre olduğunu göstermektedir (8). Yapılan çalışmalarda kavrama kuvveti ile yaş arasında yüksek bir korelasyon olduğu ve artan yaş ile birlikte kavrama kuvvetinin azaldığı gözlenmiştir $(9,10)$.

Literatürde yaşlı bireylerde üst ekstremite fonksiyonlarını ve dengeyi ayrı ayrı inceleyen birçok çalışma bulunmasına rağmen, üst ekstremite fonksiyonları ile denge arasındaki ilişkiyi inceleyen çalışmaların yetersiz olduğu belirlenmiştir. Bu çalışmanın amacı yaşlı bireylerde üst ekstremite fonksiyonları ile denge arasındaki ilişkiyi incelemektir.

\section{Gereç ve Yöntem}

Bu çalışma, Ahi Evran Üniversitesi Fizik Tedavi ve Rehabilitasyon Yüksekokulu'nda yapılmış ve 65 yaş ve üzeri 80 yaşlı birey değerlendirilerek tamamlanmıştır. Çalışmaya dahil edilme kriterleri; 65 yaş ve üzeri olmak, çalışmaya katılmaya gönüllü olmak, iletişim için yeterli bilişsel fonksiyona sahip olmak (Mini Mental Durum Testi puanının 24 ve üzeri olması), yatağa veya tekerlekli sandalyeye bağımlı olmamak, yardımsız en az 90 saniye ayakta durabilmek olarak belirlenmiştir. Mobilizasyonu kısıtlayacak derecede görme kaybı, ileri derecede işitme kayb1, mentalretardasyon, alt veya üst ekstremiteamputasyonu, yardımcı yürüme cihazı kullanımı, ciddi muskuloskeletal problem varlığı, dengeyi olumsuz etkileyecek santral sinir sistemi patolojisi, vestibüler patoloji tanısi, orta ve ileri derecede kardiyovasküler hastalığı olan bireyler ise çalışmaya dahil edilmemiştir. Çalışma "Helsinki Deklarasyonu" ilkelerine uygun olarak yürütülmüş olup Ahi Evran Üniversitesi Tıp Fakültesi Klinik Araştırmalar Etik Kurulu tarafından değerlendirilmiş ve tıbbi etik açıdan uygun bulunmuştur (karar no: 2018-06/65). Ayrıca çalışmaya katılan tüm bireyler çalışmanın amacını ve içeriğini kapsayan yazılı bir aydınlatılmış onam ile bilgilendirilmişler ve gönüllü olduklarını onam formunu imzalayarak belirtmişlerdir.

\section{Değerlendirmeler}

\section{Demografik bilgiler}

Çalışmaya katılan bireylerin yaşı, cinsiyeti, boyu, kilosu, vücut kütle indeksi kaydedilmiştir.

\section{Üst Ekstremite Fonksiyonlarının Değerlendirilmesi}

Bireylerin üst ekstremitelerini değerlendirmek için Jamar El Dinamometresi, 9 Delikli Peg Testi ve Purdue Pegboard Testi kullanılmıştır. Jamar El Dinamometresi ile kavrama kuvveti, 9 Delikli Peg Testi ve PurduePegboard Testleri ile el becerileri değerlendirilmiştir.

\section{Kavrama Kuvveti}

Kavrama kuvveti, dominant ve non dominant el için Jamar El Dinamometresi kullanılarak değerlendirilmiştir. İşlem öncesi bireyler oturur pozisyonda, omuz adduksiyonda ve nötral pozisyonda, dirsek 90 derece fleksiyonda, ön kol ve el bileği nötral pozisyonda olacak şekilde pozisyonlanmıştır (11). 
Bireylerden pozisyonlarını korumaları ve dinamometreyi olabildiğince kuvvetli bir şekilde sıkıp bırakmaları istenmiştir. Ölçüm 30 saniye aralıklarla bilateral olarak 3'er kez tekrarlanmıştır. Çıkan sonuçların ortalaması alınıp kilogram olarak kaydedilmiştir $(9,12)$.

\section{Purdue Pegboard Testi}

Parmak ucu becerisi ve el koordinasyonu hem tek taraflı hem de iki taraflı ince el becerisini ölçmeye yarayan PurduePegboard Testi (PPBT) ile değerlendirilmiştir (13). Test; çiviler, pullar ve delikli tahta düzeneğinden oluşmaktadır. Tahtada her iki tarafta 25 delikli iki paralel sıra bulunmaktadır. Çiviler ve pullar ise tahtanın üstünde ayrılan boşluklarda yer almaktadır. Test, 4 ana alt test ve üç alt testin toplamıyla oluşturulan yeni bir test sonucu olmak üzere 5 bölümden oluşmaktadır. Bunlar; dominant el (PPBT 1), non-dominant el (PPBT 2), her iki el (PPBT 3 ) ve dominant + non-dominant + her iki elin (PPBT 4) birlikte değerlendirildiği 4 ana alt test ve tüm aktivitelerin birlikte yapıldığı ek bir alt testten (PPBT 5) oluşmaktadır. Test düzeneği, bireyin kolayca ulaşabileceği şekilde hemen önüne ve rahatça oturabildiği yükseklikte bir masaya yerleştirilmiştir. İlk üç testte 30 saniye içinde maksimum sayıda çiviyi, önce dominant el ile sonra non-dominant ile ve son olarak her iki el ile eş zamanlı olarak yukardan aşağıya takmaları istenmiştir. Son alt test ise her iki eli kullanarak 60 saniyede çivileri ve pulları birleştirmesi ile gerçekleştirmiştir. Dördüncü test ayrı bir test olmayıp ilk üç bölümün puanlarının toplanmasıyla elde edilmişstir $(14,15)$.

\section{Delikli Peg Testi}

İnce parmak becerisini değerlendirmek için el beceri testi olan 9 Delikli Peg Testi (9-DPT) kullanılmıştır (16). Test, 9 delikli bir platform ve 9 çubuktan oluşmaktadır. Platform, doğrudan bireylerin önüne yerleştirilerek çubuklar bireylerin dominant el tarafında, delikler dominant olmayan el tarafında olacak şekilde ayarlanmıştır. Bireylere test kuralları anlatıldıktan sonra uygulamadan önce bireylere pratik için firsat verilmiştir. Bireylerden çubukları tahtaya olabildiğince hızlı takmaları istenmiştir. Test sonuçları, bireylerin ilk çubuğa dokunduğu andan son çubuğun platforma takıldığı ana kadar süre kronometre ile ölçülerek kaydedilmiştir. Daha sonra aynı elle 9 çubuğu sırasıyla tek tek çıkarmaları istenmiş ve çıkarma süresi kaydedilmiştir. Test, aynı yöntem kullanılarak dominant olmayan el için; platform ise bu sefer dominant olmayan elin önünde olacak şekilde döndürülerek uygulanmıştır $(16,17)$.

\section{Dengenin Değerlendirilmesi}

Bireylerin dengelerini değerlendirmek için Berg Denge Ölçeği, Tinetti Denge ve Yürüme Testi, Tek Ayak Üzerinde Durma Testi ve Biodex Denge Sistemi kullanılmıştır.

\section{Berg Denge Ölçeği}

Berg Denge Ölçeği (BDÖ), yaşlı popülasyonda denge performansını fonksiyonel olarak değerlendiren en temel testlerden biridir. Ölçek günlük yaşamda sıklıkla kullanılan 14 fonksiyonel aktiviteden (otururken ayağa kalkma, desteksiz ayakta durma, desteksiz oturma, ayakta iken oturma, transfer, gözler kapalı iken ayakta durma, bacaklar birleşikken ayakta durma, ayakta iken öne uzanma, yerden cisim alma, arkaya dönerek bakma, 360 derece dönme, sağlam taraf iskemle üzerinde durma, bir ayak önde durma ve tek ayak üstündedurma) oluşmaktadır. Aktiviteler 0-4 arası puanlanmaktadır. Bireyin aktiviteyi yapamaması durumunda 0 puan, bağımsız bir şekilde yapması durumunda 4 puan verilmektedir. Düşük puanlar bozuk dengeyi göstermektedir. En yüksek puan 56 olup 0-20 puan denge bozukluğunu, 21-40 puan kabul edilebilir bir denge varlığını, 41-56 puan iyi bir dengenin varlığını göstermektedir. Teste başlamadan önce aktiviteler tek tek bireye gösterilerek anlatılmıştır.

Aktiviteler arasında bireylere gerek duyulduğunda dinlenmeleri için firsat verilmiştir. Bireylerin güvenli bir şekilde aktiviteleri tamamlayabilmeleri için tüm test boyunca araştırmacı tarafından gözlenmiştir. Berg Denge Ölçeği, testi oluşturan 14 farklı aktivitenin yaşlı bireylere sırasıyla yaptırılmasıyla tamamlanmıştır. Her bir aktiviteden alınan puanlar toplanarak toplam test puanı hesaplanmıştır (18).

\section{Tinetti Denge ve Yürüme Testi}

Tinetti denge ve yürüme testi (TDYT), denge ve yürüme ile ilgili aktiviteleri içeren iki bölümden oluşmaktadır. Her aktivite için ayrı puanlama ve değerlendirme kriteri mevcuttur. İlk 9 maddelik kısım denge ile ilgili, sonraki 7 maddelik kısım ise yürüme ile ilgili aktiviteleri içermektedir. İlk olarak denge ile ilgili aktiviteleri içeren birinci bölüm, daha sonra yürüme ile ilgili aktiviteleri içeren ikinci bölüm parametreleri sırasıyla yaşlı bireylere yaptırılmış ve aldıkları puanlar kaydedilmiştir. Testten alınabilecek en yüksek puan 28'dir. Düşük puanlar bozuk dengeyi göstermektedir. 19 puanın altındaki puanlar yüksek, 19-23 arası puanlar orta, 24 ve üzeri puanlar düşük derecede düşme riski ile ilişkilidir (19). 


\section{Biodex Denge Sistemi}

Biodex denge sistemi (BDS) dinamik postüral denge değerlendirilmesinde güvenilir bulunmuş olup son yıllarda postüral dengeyi değerlendirmek amacıyla kullanılmaktadır. Çalışmaya katılan yaşlı bireylerin statik ve dinamik denge değerleri, anterior-posterior (AP), medial-lateral (ML) ve toplam değer (OS) olmak üzere Biodex Denge Sistemi ile ölçülmüştür. Bu sistem, içeriğindeki yazılım (Biodex, Versiyon 3.1, Biodex, Inc.,Shirley New York) sayesinde dengeyi objektif olarak ölçmeye olanak sağlamaktadır. Değerlendirmeye ilk olarak statik denge ölçümü ile başlanmıştır. Yaşlı bireyler gözler açık, ayaklar çıplak (çorap hariç) platform üzerinde kollar gövde yanında serbest pozisyonlanarak dengede durmaları söylenmiştir. Ölçümleri toplam 20'şer saniye ve dinlenme aralıkları da 10 'ar saniyeden oluşan 3 test uygulanmış ve sonuç ortalaması cihaz tarafından otomatik olarak hesaplanmıştır.

Daha sonra dinamik denge ölçümüne geçilmiş ve platform dengeyi bozucu şekilde hareket ediyor olarak ayarlanmıştır. Bu değerlendirme için de statik dengedeki aynı pozisyon, aynı ölçüm ve dinlenme süreleri uygulanmıştır. $\mathrm{Bu}$ ölçüm de 3 kere tekrarlanmış ve çıkan sonuç kaydedilmiştir (20).

\section{Tek Ayak Üzerinde Durma Testi}

Tek ayak üzerinde durma testi (TAÜDT), yaşlı bireyler için uygun, geçerli bir denge değerlendirme yöntemidir ve fizyoterapistler ile mesleki terapistler tarafından yaygın olarak kullanılmaktadır. Test sırasında bireylerden gözler açık olmak üzere sırasıyla sağ ve sol ayakları üzerinde, herhangi bir yerden destek almadan mümkün olduğunca uzun süre ayakta durmaları için özel talimatlar verilmektedir. Test 30 saniyelik aralıklarla yapılmıştır. Testi tamamlama zamanı olarak ayağın yerden kaldırılması ile yere indirilmesi arasında geçen süre standart bir kronometreyle ölçülerek kaydedilmiştir $(21,22)$.

\section{Yaşam Kalitesinin Değerlendirilmesi}

Bireylerin yaşam kalitelerini değerlendirmek için Dünya Sağlık Örgütü Yaşam Kalitesi Ölçeği-Yaşlı Modülü (WHOQOL-OLD) kullanılmıştır. Bu ölçek, Power ve ark. tarafından geliştirilmiş ve ölçeğin Türkçe geçerlilik ve güvenilirlik çalışması Eser $\mathrm{S}$. ve ark. tarafından yapılmıştır (23)

\section{İstatistiksel Analizi}

Çalışmamızda veriler SPSS 22.0 programı ile analiz edildi. Verilerin normal dağılım uygunluğu KolmogorovSimirnov testi ve SkewnessKurtosis testi ile analiz edildi. Verilerin normal dağılıma uygun olduğu tespit edildi. Çalışmamızda bireylerin demografik özellikleri, Jamar El Dinamometresi, 9-DPT, PPBT, BDÖ, TDYT, TAÜDT, BDS ve WHOQOL-OLD sonuçlarının birbirleriyle ilişkili olup olmadığına Pearson Korelasyon Testi ile bakıldı. Çalışmamızda istatiksel anlamlılık düzeyi $\mathrm{p}<0,05$ olarak kabul edildi. Çalışmamızda güç analizi post-hoc yapıldı. $|r|: 0,60$ etki genişliğinde $\% 80$ güç elde etmek için 78 bireye ihtiyaç olduğu belirlendi.

Aktiviteler arasında bireylere gerek duyulduğunda dinlenmeleri için firsat verilmiştir. Bireylerin güvenli bir şekilde aktiviteleri tamamlayabilmeleri için tüm test boyunca araştırmacı tarafından gözlenmiştir. Berg Denge Ölçeği, testi oluşturan 14 farklı aktivitenin yaşlı bireylere sırasıyla yaptırılmasıyla tamamlanmıştır. Her bir aktiviteden alınan puanlar toplanarak toplam test puanı hesaplanmıştır (18).

\section{Tinetti Denge ve Yürüme Testi}

Tinetti denge ve yürüme testi (TDYT), denge ve yürüme ile ilgili aktiviteleri içeren iki bölümden oluşmaktadır. Her aktivite için ayrı puanlama ve değerlendirme kriteri mevcuttur. İlk 9 maddelik kısım denge ile ilgili, sonraki 7 maddelik kısım ise yürüme ile ilgili aktiviteleri içermektedir. İlk olarak denge ile ilgili aktiviteleri içeren birinci bölüm, daha sonra yürüme ile ilgili aktiviteleri içeren ikinci bölüm parametreleri sırasıyla yaşlı bireylere yaptırılmış ve aldıkları puanlar kaydedilmiştir. Testten alınabilecek en yüksek puan 28'dir. Düşük puanlar bozuk dengeyi göstermektedir. 19 puanın altındaki puanlar yüksek, 19-23 arası puanlar orta, 24 ve üzeri puanlar düşük derecede düşme riski ile ilişkilidir (19).

\section{Biodex Denge Sistemi}

Biodex denge sistemi (BDS) dinamik postüral denge değerlendirilmesinde güvenilir bulunmuş olup son yıllarda postüral dengeyi değerlendirmek amaciyla kullanılmaktadır. Çalışmaya katılan yaşı ı bireylerin statik ve dinamik denge değerleri, anterior-posterior (AP), medial-lateral (ML) ve toplam değer (OS) olmak üzere Biodex Denge Sistemi ile ölçülmüştür. 
$\mathrm{Bu}$ sistem, içeriğindeki yazılım (Biodex, Versiyon 3.1, Biodex, Inc.,Shirley New York) sayesinde dengeyi objektif olarak ölçmeye olanak sağlamaktadır. Değerlendirmeye ilk olarak statik denge ölçümü ile başlanmıştır. Yaşıı bireyler gözler açık, ayaklar çıplak (çorap hariç) platform üzerinde kollar gövde yanında serbest pozisyonlanarak dengede durmaları söylenmiştir. Ölçümleri toplam 20'şer saniye ve dinlenme aralıkları da 10'ar saniyeden oluşan 3 test uygulanmış ve sonuç ortalaması cihaz tarafından otomatik olarak hesaplanmıştır.

Daha sonra dinamik denge ölçümüne geçilmiş ve platform dengeyi bozucu şekilde hareket ediyor olarak ayarlanmıştır. Bu değerlendirme için de statik dengedeki aynı pozisyon, aynı ölçüm ve dinlenme süreleri uygulanmıştır. Bu ölçüm de 3 kere tekrarlanmış ve çıkan sonuç kaydedilmiştir (20).

\section{Tek Ayak Üzerinde Durma Testi}

Tek ayak üzerinde durma testi (TAÜDT), yaşlı bireyler için uygun, geçerli bir denge değerlendirme yöntemidir ve fizyoterapistler ile mesleki terapistler tarafından yaygın olarak kullanılmaktadır. Test sırasında bireylerden gözler açık olmak üzere sırasıyla sağ ve sol ayakları üzerinde, herhangi bir yerden destek almadan mümkün olduğunca uzun süre ayakta durmaları için özel talimatlar verilmektedir. Test 30 saniyelik aralıklarla yapılmıştır. Testi tamamlama zamanı olarak ayağın yerden kaldırılması ile yere indirilmesi arasında geçen süre standart bir kronometreyle ölçülerek kaydedilmiştir $(21,22)$.

\section{Yaşam Kalitesinin Değerlendirilmesi}

Bireylerin yaşam kalitelerini değerlendirmek için Dünya Sağlık Örgütü Yaşam Kalitesi Ölçeği-Yaşlı Modülü (WHOQOL-OLD) kullanılmıştır. Bu ölçek, Power ve ark. tarafından geliştirilmiş ve ölçeğin Türkçe geçerlilik ve güvenilirlik çalışması Eser $\mathrm{S}$. ve ark. tarafından yapılmıştır (23).

\section{Istatistiksel Analizi}

Çalışmamızda veriler SPSS 22.0 programı ile analiz edildi. Verilerin normal dağılım uygunluğu KolmogorovSimirnov testi ve SkewnessKurtosis testi ile analiz edildi. Verilerin normal dağılıma uygun olduğu tespit edildi. Çalışmamızda bireylerin demografik özellikleri, Jamar El Dinamometresi, 9-DPT, PPBT, BDÖ, TDYT, TAÜDT, BDS ve WHOQOL-OLD sonuçlarının birbirleriyle ilişkili olup olmadığına Pearson Korelasyon Testi ile bakıldı. Çalışmamızda istatiksel anlamlılık düzeyi $\mathrm{p}<0,05$ olarak kabul edildi. Çalışmamızda güç analizi post-hoc yapıldı. $|r|: 0,60$ etki genişliğinde $\% 80$ güç elde etmek için 78 bireye ihtiyaç olduğu belirlendi. Çalışmamıza dahil edilen 80 birey ile çalışmamızın gücünün $\% 83$ olduğu görüldü.

\section{Bulgular ve Analiz}

Çalışmaya dahil edilen bireylerin fiziksel özellikleri Tablo 3.1'de gösterilmiştir. Toplam 80 yaşlı birey çalışmaya katılmış olup bireylerin yaş aralığı 65-82'dir. Bireylerin Jamar El Dinamometresi, 9-DPT ve PPBT sonuçları ile BDÖ, TDYT, TAÜDT sonuçları arasında anlamlı ilişki bulunmuştur $(\mathrm{p}<0,05)$ (Tablo 3.2).

Tablo 3.1. Bireylerin Fiziksel Özellikleri

\begin{tabular}{|c|c|c|c|}
\hline & $\begin{array}{c}\text { Minimum } \\
(\mathrm{n}=\mathbf{8 0})\end{array}$ & $\begin{array}{c}\text { Maksimum } \\
(\mathrm{n}=\mathbf{8 0})\end{array}$ & $\begin{array}{c}\mathrm{X} \pm \mathrm{SS} \\
(\mathrm{n}=\mathbf{8 0})\end{array}$ \\
\hline Yaș (yıl) & 65 & 82 & $69,10 \pm 4,20$ \\
\hline Boy uzunluğu (cm) & 130 & 185 & $164,11 \pm 7,54$ \\
\hline Vücut ağırlığı (kg) & 58 & 130 & $83,66 \pm 13,37$ \\
\hline Vücut kütle indeksi $\left(\mathrm{kg} / \mathrm{m}^{2}\right)$ & 21 & 48,80 & $31,01 \pm 5,20$ \\
\hline
\end{tabular}


Tablo 3.2. Bireylerin Jamar El Dinamometresi, Dokuz Delikli Peg Testi ve PurduePegboard Test Sonuçlarıyla Berg Denge Ölçeği, Tinetti Denge ve Yürüme Testi ve Tek Ayak Üzerinde Durma Test Sonuçlarının Karşılaştırılması

\begin{tabular}{llllll}
\hline & & \multicolumn{1}{c}{ BDÖ } & \multicolumn{1}{c}{ TDYT } & TAÜDT sağ & TAÜDT sol \\
\hline JED sağ & $\mathrm{r}$ & 0,590 & 0,630 & 0,501 & 0,502 \\
& $\mathrm{p}$ & $<0,001$ & $<0,001$ & $<0,001$ & $<0,001$ \\
\hline JED sol & $\mathrm{r}$ & 0,565 & 0,548 & 0,497 & 0,502 \\
& $\mathrm{p}$ & 0,001 & 0,001 & $<0,001$ & $<0,001$ \\
9-DPT sağ takma & $\mathrm{r}$ & $-0,544$ & $-0,515$ & $-0,307$ & $-0,300$ \\
& $\mathrm{p}$ & $<0,001$ & $<0,001$ & 0,006 & 0,007 \\
9-DPT sağ çıkarma & $\mathrm{r}$ & $-0,484$ & $-0,485$ & $-0,282$ & $-0,318$ \\
& $\mathrm{p}$ & $<0,001$ & $<0,001$ & 0,011 & 0,004 \\
9-DPT sol takma & $\mathrm{r}$ & $-0,542$ & $-0,574$ & $-0,241$ & $-0,254$ \\
& $\mathrm{p}$ & $<0,001$ & $<0,001$ & 0,031 & 0,023 \\
9-DPT sol çוkarma & $\mathrm{r}$ & $-0,459$ & $-0,466$ & $-0,286$ & $-0,313$ \\
& $\mathrm{p}$ & $<0,001$ & $<0,001$ & 0,010 & 0,005 \\
PPBT 1 & $\mathrm{r}$ & 0,642 & 0,643 & 0,454 & 0,458 \\
& $\mathrm{p}$ & $<0,001$ & $<0,001$ & $<0,001$ & $<0,001$ \\
PPBT 2 & $\mathrm{r}$ & 0,562 & 0,527 & 0,369 & 0,380 \\
& $\mathrm{p}$ & $<0,001$ & $<0,001$ & 0,001 & 0,001 \\
PPBT 3 & $\mathrm{r}$ & 0,510 & 0,526 & 0,502 & 0,518 \\
& $\mathrm{p}$ & $<0,001$ & $<0,001$ & $<0,001$ & $<0,001$ \\
PPBT 4 & $\mathrm{r}$ & 0,629 & 0,623 & 0,489 & 0,507 \\
& $\mathrm{p}$ & $<0,001$ & $<0,001$ & $<0,001$ & $<0,001$ \\
PPBT 5 & $\mathrm{r}$ & 0,528 & 0,459 & 0,486 & 0,547 \\
& $\mathrm{p}$ & $<0,001$ & $<0,001$ & $<0,001$ & $<0,001$ \\
\hline \hline
\end{tabular}

p<0,05; PurduePegboard Testi: PPBT (PPBT 1: dominant el, PPBT 2: non-dom inant el, PPBT 3: her iki el, PPBT 4: dominant + non-dom inant t her iki el ve PPBT 5: tüm aktiviteler birlikte), 9-DPT: 9 Delikli Peg Testi, BDÖ: Berg Denge Ölçeği, TDYT: Tinetti denge ve yürüme testi, TAÜDT: Tek ayak üzerinde duma testi, Jamar El Dinamometresi: JED

Bireylerin Jamar El Dinamometresi sonuçlarıyla statik BDS sonuçları arasında yalnızca sağ taraf Jamar El Dinamometresi ile OS ve ML ölçüm sonuçları arasında anlamlı ilişki bulunurken $(\mathrm{p}<0,05)$, hem sağ hem de sol taraf Jamar El Dinamometresi sonuçlarıyla dinamik BDS sonuçlarının tümü arasında anlamlı ilişki bulunmuştur $(\mathrm{p}<0,05)$ (Tablo 3.3).

Tablo 3.3. Bireylerin Jamar El Dinamometresi, Dokuz Delikli Peg Testi ve PurduePegboard Test Sonuçlarıyla Statik ve Dinamik Biodex Denge Sistemi Ölçüm Sonuçlarının Karşılaştırılması

\begin{tabular}{|c|c|c|c|c|c|c|c|}
\hline & & \multicolumn{3}{|c|}{ Biodex Denge Sistemi (statik) } & \multicolumn{3}{|c|}{ Biodex Denge Sistemi (dinamik) } \\
\hline & & OS & AP & ML & OS & AP & ML \\
\hline \multirow[t]{2}{*}{ JED sağ } & $\mathrm{r}$ & $-0,223$ & $-0,093$ & $-0,275$ & $-0,225$ & $-0,245$ & $-0,333$ \\
\hline & $\mathrm{p}$ & 0,047 & 0,410 & 0,014 & 0,022 & 0,028 & 0,003 \\
\hline \multirow[t]{2}{*}{ JED sol } & $\mathrm{r}$ & $-0,132$ & $-0,096$ & $-0,125$ & $-0,242$ & $-0,223$ & $-0,360$ \\
\hline & $\mathrm{p}$ & 0,242 & 0,396 & 0,271 & 0,031 & 0,046 & 0,001 \\
\hline \multirow[t]{2}{*}{ 9-DPT sağ takma } & $\mathrm{r}$ & 0,288 & 0,262 & 0,263 & 0,308 & 0,319 & 0,300 \\
\hline & $\mathrm{p}$ & 0,009 & 0,019 & 0,018 & 0,005 & 0,004 & 0,007 \\
\hline \multirow[t]{2}{*}{ 9-DPT sağ çıkarma } & $\mathrm{r}$ & 0,209 & 0,094 & 0,259 & 0,294 & 0,208 & 0,193 \\
\hline & $\mathrm{p}$ & 0,062 & 0,405 & 0,020 & 0,008 & 0,064 & 0,086 \\
\hline \multirow{2}{*}{ 9-DPT sol takma } & $\mathrm{r}$ & 0,239 & 0,205 & 0,230 & 0,239 & 0,142 & 0,238 \\
\hline & $\mathrm{p}$ & 0,033 & 0,069 & 0,041 & 0,033 & 0,208 & 0,034 \\
\hline \multirow[t]{2}{*}{ 9-DPT sol çlkarma } & $\mathrm{r}$ & 0,142 & 0,071 & 0,174 & 0,258 & 0,103 & 0,184 \\
\hline & $\mathrm{p}$ & 0,209 & 0,534 & 0,123 & 0,021 & 0,365 & 0,103 \\
\hline \multirow[t]{2}{*}{ PPBT 1} & $\mathrm{r}$ & $-0,275$ & $-0,217$ & $-0,242$ & $-0,305$ & $-0,254$ & $-0,276$ \\
\hline & $\mathrm{p}$ & 0,013 & 0,053 & 0,031 & 0,006 & 0,023 & 0,013 \\
\hline \multirow[t]{2}{*}{ PPBT 2} & $\mathrm{r}$ & $-0,253$ & $-0,149$ & $-0,266$ & $-0,279$ & $-0,164$ & $-0,304$ \\
\hline & $\mathrm{p}$ & 0,024 & 0,186 & 0,017 & 0,012 & 0,146 & 0,006 \\
\hline \multirow[t]{2}{*}{ PPBT 3} & $\mathrm{r}$ & $-0,152$ & $-0,100$ & $-0,155$ & $-0,255$ & $-0,211$ & $-0,322$ \\
\hline & $\mathrm{p}$ & 0,179 & 0,377 & 0,170 & 0,022 & 0,061 & 0,004 \\
\hline \multirow[t]{2}{*}{ PPBT 4} & $\mathrm{r}$ & $-0,247$ & $-0,168$ & $-0,244$ & $-0,310$ & $-0,227$ & $-0,329$ \\
\hline & $p$ & 0,027 & 0.137 & 0,029 & 0,005 & 0,043 & 0,003 \\
\hline \multirow[t]{2}{*}{ PPBT 5} & $\mathrm{r}$ & $-0,182$ & $-0,118$ & $-0,184$ & $-0,338$ & $-0,331$ & $-0,463$ \\
\hline & $\mathrm{p}$ & 0,105 & 0,297 & 0,102 & 0,002 & 0,003 & $<0,001$ \\
\hline
\end{tabular}

P her iki el, PPBT 4: dom inant + non-dominant + her iki el ve PPBT 5: tüm aktiviteler birlikte), 9-DPT: 9 Delikli Peg Testi, Biodex denge sistemi (AP: anterior-posterior, ML: medial-lateral ve OS: toplam değer) 
Sağ taraf 9-DPT takma sonuçlarının tümü ile BDS sonuçları arasında anlamlı ilişki bulunurken $(p<0,05)$, sol taraf 9-DPT takma sonuçlarından hem statik hem de dinamik AP sonuçları hariç tüm BDS sonuçları ile anlamlı ilişski bulunmuştur $(p<0,05)$. Sağ taraf çıkarma sonuçları ile BDS sonuçları arasında yalnızca statik ML ve dinamik OS ile anlamlı ilişki bulunurken $(\mathrm{p}<0,05)$, sol taraf çıkarma sonuçlarından yalnızca dinamik OS ile anlamlı ilişki bulunmuştur ( $\mathrm{p}<0,05)$ (Tablo 3.3).

PPBT 1 ve PPBT 4 sonuçları ile BDS sonuçları arasında yalnızca statik AP hariç BDS sonuçlarının tümüyle anlamlı ilişki bulunmuştur $(\mathrm{p}<0,05)$. PPBT 2 sonuçları ile BDS sonuçları arasında hem statik hem de dinamik AP sonuçları hariç diğer sonuçlar ile anlamlı ilişki bulunmuştur $(\mathrm{p}<0,05)$. PPBT 3 sonuçları ile BDS sonuçları arasında yalnızca dinamik OS ve ML ölçümleri arasında anlamlı ilişki bulunurken $(\mathrm{p}<0,05)$, diğer sonuçlar arasında anlamlı ilişki bulunmamıştır $(p>0,05)$. PPBT 5 sonuçları ile statik BDS sonuçları arasında anlamlı ilişki bulunmazken $(p>0,05)$, dinamik BDS sonuçlarının tümü ile anlamlı ilişki bulunmuştur $(\mathrm{p}<0,05)$ (Tablo 3.3).

Çalışmaya katılan yaşlı bireylerin Jamar El Dinamometresi, 9-DPT ve PPBT sonuçları ile Dünya Sağlık Örgütü Yaşam Kalitesi Ölçeği-Yaşlı Modülü puanları arasındaki ilişki Tablo 3.4'te gösterilmiştir. Yapılan analize göre PPBT 1 sonucu ile yaşam kalitesi testi yakınlık alt parametresi arasında anlamlı ilişki bulunmuş olup $(p<0,05)$ diğer sonuçlar arasında herhangi bir ilişki bulunmamıştır $(\mathrm{p}>0,05)$.

Tablo 3.4. Bireylerin Jamar El Dinamometresi, Dokuz Delikli Peg Testi ve PurduePegboard Test Sonuçlarıyla Dünya Sağlık Örgütü Yaşam Kalitesi Ölçeği-Yaşlı Modülü Puanlarının Karşılaştırılması

\begin{tabular}{|c|c|c|c|c|c|c|c|c|}
\hline & & $\begin{array}{c}\text { WHOQOL } \\
\text {-OLD }\end{array}$ & $\begin{array}{c}\text { Duyusal } \\
\text { Yetiler }\end{array}$ & Özerklik & Faaliyetler & $\begin{array}{l}\text { Sosyal } \\
\text { Katılım }\end{array}$ & $\begin{array}{c}\text { Ölüm ve } \\
\text { ÖImek }\end{array}$ & Yakınlık \\
\hline \multirow{2}{*}{ JED sağ } & $r$ & 0,005 & $-0,113$ & $-0,009$ & 0,103 & $-0,072$ & $-0,045$ & 0,069 \\
\hline & $\mathrm{p}$ & 0,967 & 0,319 & 0,940 & 0,363 & 0,523 & 0,689 & 0,545 \\
\hline \multirow[t]{2}{*}{ JED sol } & $\mathrm{r}$ & 0,042 & $-0,059$ & $-0,020$ & 0,130 & $-0,094$ & $-0,042$ & 0,083 \\
\hline & $\mathrm{p}$ & 0,714 & 0,602 & 0,861 & 0,251 & 0,406 & 0,711 & 0,464 \\
\hline \multirow[t]{2}{*}{ 9-DPT sağ takma } & $\mathrm{r}$ & 0,081 & 0,111 & 0,018 & $-0,029$ & 0,044 & 0,095 & $-0,405$ \\
\hline & $\mathrm{p}$ & 0,475 & 0,327 & 0,872 & 0,800 & 0,699 & 0,404 & 0,690 \\
\hline \multirow[t]{2}{*}{ 9-DPTsağ çıkarma } & $\mathrm{r}$ & $-0,089$ & 0,076 & $-0,051$ & $-0,095$ & 0,042 & $-0,047$ & $-0,119$ \\
\hline & $\mathrm{p}$ & 0,431 & 0,503 & 0,650 & 0,401 & 0,712 & 0,678 & 0,292 \\
\hline \multirow[t]{2}{*}{ 9-DPT sol takma } & $\mathrm{r}$ & $-0,024$ & 0,137 & $-0,009$ & $-0,066$ & $-0,051$ & 0,034 & $-0,024$ \\
\hline & $\mathrm{p}$ & 0,833 & 0,226 & 0,938 & 0,561 & 0,652 & 0,763 & 0,836 \\
\hline \multirow[t]{2}{*}{ 9-DPT sol çıkarma } & $\mathrm{r}$ & $-0,072$ & 0,080 & $-0,114$ & $-0,109$ & $-0,074$ & 0,105 & $-0,107$ \\
\hline & $\mathrm{p}$ & 0,525 & 0,479 & 0,316 & 0,336 & 0,514 & 0,352 & 0,344 \\
\hline \multirow[t]{2}{*}{ PPBT 1} & $\mathrm{r}$ & 0,044 & $-0,170$ & 0,088 & 0,186 & 0,011 & $-0,185$ & 0,243 \\
\hline & $\mathrm{p}$ & 0,698 & 0,131 & 0,436 & 0,098 & 0,924 & 0,101 & $0,030^{*}$ \\
\hline \multirow[t]{2}{*}{ PPBT 2} & $\mathrm{r}$ & 0,146 & 0,006 & $-0,032$ & 0,146 & $-0,013$ & 0,011 & 0,200 \\
\hline & $\mathrm{p}$ & 0,197 & 0,961 & 0,779 & 0,195 & 0,909 & 0,926 & 0,076 \\
\hline \multirow[t]{2}{*}{ PPBT 3} & $\mathrm{r}$ & 0,130 & $-0,085$ & 0,038 & 0,182 & $-0,011$ & 0,047 & 0,097 \\
\hline & $\mathrm{p}$ & 0,251 & 0,454 & 0,739 & 0,107 & 0,920 & 0,679 & 0,393 \\
\hline \multirow[t]{2}{*}{ PPBT 4} & $\mathrm{r}$ & 0,122 & $-0,111$ & 0,039 & 0,200 & $-0,005$ & $-0,039$ & 0,208 \\
\hline & $\mathrm{p}$ & 0,280 & 0,327 & 0,728 & 0,075 & 0,966 & 0,731 & 0,064 \\
\hline \multirow[t]{2}{*}{ PPBT 5} & $\mathrm{r}$ & 0,154 & $-0,085$ & 0,040 & 0,123 & $-0,047$ & 0,113 & 0,202 \\
\hline & $\mathrm{p}$ & 0,174 & 0,453 & 0,722 & 0,278 & 0,676 & 0,318 & 0,072 \\
\hline
\end{tabular}

\section{Tartıșma}

Bu çalışmanın sonucunda, yaşlı bireylerde üst ekstremite fonksiyonları ile denge arasında anlamlı bir ilișki bulunmuştur. Literatür araştırmalarımıza göre bu çalışma üst ekstremite fonksiyonları ile denge arasındaki ilişkiyi inceleyen az sayıda çalışmalardan biridir.

Yaş ile birlikte kavrama kuvveti değerlerinde azalmaya birçok faktör neden olmaktadır ve sonuç olarak günlük yaşam aktivitelerinde yetersizlikler meydana gelmektedir $(24,25)$. Bu nedenle bireylerin özellikle üst ekstremite işlevlerindeki yetersizliği belirleme ve takibinde kavra- ma kuvvetinin ölçümü yardımcı olabilmektedir (26). Bizim çalışmamız sonucunda hem sağ hem de sol taraf kavrama kuvveti ile BDÖ, TDYT, TAÜDT sonuçları arasında pozitif yönde anlamlı ilişki bulunmuştur. Yani kavrama kuvveti arttığı zaman denge durumu daha stabil bir hale gelmiştir.

Jamar El Dinamometresi sonuçlarıyla tüm dinamik BDS sonuçları arasında negatif yönde anlamlı ilişki bulunurken sağ taraf Jamar El Dinamometresi ile yalnızca statik AP sonucu ile ve sol taraf Jamar El Dinamometresi ile statik BDS sonuçlarının tümü ile anlamlı ilişki bulunmamıştır. 
Davis ve ark. kadınların çoğunlukta olduğu bir çalışmada (9704 denek), kavrama kuvveti ve kalça abdüktör kuvveti iyi olan bireylerin giyinme ve bakım, kalkma, yeme, yürüme, hijyen, uzanma, kavrama aktivitelerini içeren günlük yaşam aktivite skorlarının daha iyi olduğunu belirtmişlerdir (27). Stevens ve ark. yaşları 63-73 aralığında değişen bireyleri dahil ettikleri çalışmalarında erkek bireylerde daha yüksek kavrama kuvvetinin daha iyi bir denge ile ilişkili olduğunu ancak kadınlarda böyle bir ilişki olmadığını belirtmişlerdir. Stevens ve ark. ayrıca kavrama kuvvetinin bu yaş grubunda fiziksel performansın iyi bir işareti olduğunu bildirmişlerdir (28). Sirola ve ark. yaptıkları bir çalışmada postmenopozal kadınlarda kavrama ve kuadriseps kuvveti ile denge ve squat testleri arasında pozitif korelasyon olduğunu gözlemlemişlerdir (29). Bizim çalışmamız literatürde yapılan çalışmalarla benzerlik göstermektedir. Kavrama kuvveti arttıkça denge paremetrelerinin artacağı sonucuna varılmıştır.

Bireylerin 9-DPT ve PPBT sonuçları ile BDÖ, TDYT ve TAÜDT sonuçları arasında anlamlı ilişki bulunmuştur. $\mathrm{Bu}$ sonuca göre bireylerin 9 DPT tamamlama süreleri azaldıkça ve PPBT puanları arttıkça dengenin daha iyi olduğu görülmüştür. Sağ taraf 9-DPT takma sonuçlarının tümüyle, çıkarma sonuçlarının ise statik ML ve dinamik OS ölçümleriyle BDS arasında pozitif yönde anlamlı ilişki bulunmuştur. Sol taraf 9-DPT takma sonuçları ile hem statik hem dinamik BDS sonuçları arasında OS ve ML arasında pozitif yönde anlamlı ilişki bulunmuştur.Sol taraf 9-DPT çıkarma sonuçları ile ise hem statik hem dinamik BDS sonuçları arasında sadece dinamik OS sonucu arasında anlamlı ilişki bulunmuş olup bunun pozitif yönde olduğu tespit edilmiştir. PPBT 1 sonuçları ile BDS arasında yalnızca statik AP sonucu hariç, PPBT 2 sonuçları ile BDS arasında ise hem statik hem dinamik AP ölçümleri hariç, BDS sonuçlarının tümüyle negatif yönde anlamlı ilişki bulunmuştur. PPBT 3 sonuçları ile BDS arasında yalnızca dinamik OS ve ML ölçümleri ile negatif yönde anlamlı ilişki bulunmuştur. PPBT 4 sonuçları ile BDS sonuçları arasında yalnızca statik AP ölçümü hariç diğer BDS sonuçlarının tümü arasında negatif yönde anlamlı ilişki bulunmuştur. PPBT 5 sonuçları ile dinamik BDS sonuçlarının tümü arasında negatif yönde anlamlı ilişki bulunmuştur.

Ashburn ve ark. inme geçirmiş bireylerde düşme riskini araştırdıkları çalışmalarında nörolojik motor kaybı Rivermead motor değerlendirmesi ve dengeyi ise BDÖ ile değerlendirmişlerdir. Sonuç olarak üst ekstremitedisfonksiyonunun düşme riski ile ilişkili olduğunu, daha iyi üst ekstremite fonksiyonuna sahip bireylerde düşme riskinin daha az olduğunu gözlemlemişlerdir (30). Zulkaplı ve ark. yaptıkları bir çalışmada serebralpalsili çocuklarda postüral kontrolün üst ekstremite fonksiyonları üze- rinde etkisinin olduğunu bulmuşlardır (31). Horak ve ark. Çalışmalarında hemiplejik hastalarda üst ekstremiteparazisinin artmasının dengenin bozulmasına etki ettiğini bildirmişlerdir (32). Literatür incelendiğinde üst ekstremitefonksiyonları ile denge arasındaki ilişkiye farklı popülasyonlarda ve semptomatik bireylerde araştırıldığ tespit edilmiş olup sonuç olarak üst ekstremite fonksiyonları ile denge arasında ilişkinin varlığını belirtmektedirler. Bizim çalışmamızda asemptomatik yaşlı bireylerde üst ekstremite fonksiyonları ile denge parametreleri arasındaki ilişkiye bakılmıştır. Sonuç olarak üst ekstremite fonksiyonlarının azalması ile dengenin azaldığı tespit edilmiş olup, çalışmaya dahil edilen bireyler farklı olsa da sonuçların benzer olduğu belirlenmiştir. Ayrıca literatürde dengenin azalması ile mi üst ekstemite fonksiyonlarının etkilendiği yoksa üst ekstremite fonksiyonlarının azalması ile mi dengenin etkilendiği bir araştırma konusudur. $\mathrm{Bu}$ konu ile ilgili ileriki çalışmalara ihtiyaç duyulmaktadır. Yaş ile birlikte fiziksel kapasite azalmakta ve bu durum yaşlı bireylerde fonksiyonel bağımsızlıkların kısıtlanmasına neden olmaktadır. Fiziksel yetersizlikler, ağrılar, bilişsel bozukluklar, sağlık hizmeti kullanımı ve sosyal izolasyon gibi sorunlar yaşlı bireylerin sağlıkla ilgili yaşam kalitesini bozan faktörler arasında yer almaktadır (33). Bu çalışmada yapılan analiz sonucunda Jamar El Dinamometresi, PurduePeg Board ve 9-DPT sonuçlarıyla WHOQOL-OLD arasında anlamlı bir ilişki bulunmamıştır. Literatürde yaşam kalitesinin üst ekstremitenin fiziksel fonksiyonlarıyla ilişkisini inceleyen çalışmaların bulunduğu ve bunların çeşitli hastalıklara sahip bireylerle yapılmış olduğu tespit edilmiştir $(34,35)$. Bu konuyla ilgili asemptomatik yaşlı bireylerle yapılan çalışmaya rastlanılmamış olup daha fazla çalışmaya ihtiyaç duyulmaktadır. $\mathrm{Bu}$ çalışmanın güçlü yönlerinden biri yaşlı bireylerin denge parametrelerini etkileyen bir etmeninde üst ekstremite fonksiyonlarında ki kısıtlama olabileceğini göstermiş olmasıdır. Çalışmanın zayıf yönü olarak, çalışmaya katılan bireylerin değerlerini incelerken kadınerkek olarak gruplara ayrılıp, analiz yapılmamasıdır.

\section{Sonuç}

$\mathrm{Bu}$ çalışmanın sonucunda, yaşlı bireylerde üst ekstremite fonksiyonları ile denge arasında anlamlı bir ilişki bulunmuştur. Literatür araştırmalarımıza göre bu çalışma üst ekstremite fonksiyonları ile denge arasındaki ilişkiyi inceleyen az sayıda çalışmalardan biridir. Yaşlı bireylerde üst ekstremite fonksiyonları ile ilgili tedavi yaklaşımlarının bozulan denge ve buna bağlı günlük yaşam aktivitelerinde yaşanan sorunlar için yararlı olacağını düşünmekteyiz. 
1. Desrosiers J, Hébert R, Bravo G, et al. Age-relatedchanges in upper extremity performance of elderlypeople: a longitudinal study. Exp Gerontol. 1999; 34:393-405.

2. Williams ME, Hadle NM, Earp JL. Manual ability as a marker of dependency in geriatric women. J Chronic Dis. 1982; 35:115-22.

3. Neil B, Alexander MD. Posturalcontrol in olderadults. J AmGeriatrSoc. 1994; 42:93-108.

4. Soyuer F, Şenol V, Elmalı F. Huzurevinde kalan 65 yaş ve üstündeki bireylerin, fiziksel aktivite, denge ve mobilite fonksiyonları. Van T1p Derg. 2012; 19:116-21.

5. Abrahamová D, Hlavačka F. Age-relatedchanges of human balance during quiet stance. Physiol. Res. 2008;57: 957-64.

6. Felsenthal G, Ference TS, Young MA. Aging of organ systems. In: Gonzales EG, Myers SA, Edelstein JE, Lieberman JS, Downey JA, editors. Downey and Darling's Physiological Basis of Rehabilitation Medicine. 3th ed. Boston: Butter woth Heinemann, 2001. p.561-77.

7. Shiffman ML. Effects of aging on adulthandfunction. Am J OccupTher. 1992; 46:785-92.

8. Shahida MS, Zawiah MDS, Case K. Therelationshipbetween anthropometry and hand grip strengt hamong elderly Malaysians. Int J IndErgon. 2015; 50:17-25.

9. Mathiowetz V, Kashman N, Volland G, et al. Grip andpinchstrenght: normative data for adults. Arch Phys Med Rehabil. 1985; 66:69-74.

10. Hackel ME, Wolfe GA, Bang SM, et al. Changes in hand function in the aging adult as determined by the Jebsen Test of Hand Function. Phys Ther. 1992; 72:373-7.

11. Limaye V, Frankham A, Disney A, et al. Evaluation of hand function in patient sunder going long termhaemodialysis. Ann RheumDis. 2001; 60:278-80.

12. Hunter JM, Mackin EJ, Callahan AD, editors. Rehabilitation of thehand: Surgeryandtherapy. Missouri: Mosby 1995 .

13. Cederlund $\mathrm{R}$. Theuse of dexteritytests in hand rehabilitation. Scand J OccupTher. 1995; 99-104.

14. Lee $\mathrm{P}$, Liu $\mathrm{CH}$, Fan $\mathrm{CW}$, et al. The test-retestreliabilityand the minimal detectable change of the Purdu epegboard test in schizophrenia.J Formos Med Assoc. 2013; 112:332-7.

15. Desrosiers J, Hébert R, Bravo G, et al. The PurduePegboard Test: normative data for people aged 60 andover. Disabil Rehabil. 1995; 17:217-24.

16. Wang YC, Bohannon RW, Kapellusch J, et al. Dexterity as measured with the 9-Hole Peg Test (9-HPT) acrossthe agespan. Journal of HandTherapy. 2015; 28:53-60.
17. Oxford Grice K, Vogel KA, Le V, et al. Adult normsfor a commerci allyavailable Nine Hole Peg Test for fingerdexterity. Am J OccupTher. 2003; 57:570-3.

18. Bogle Thorbahn LD, Newton RA. Use of the BergBalance Test toPredictFalls in Elderly Persons. Phys Ther. 1996; 76:576-83.

19. Tinetti, M. E. Performance-oriented assessment of mobility problems in elderly patients. J Am Geriatr Soc, 1986; 34:119-26.

20. Baldwin SL, VanArnam TW, Ploutzsnyder LL. Reliability of dynamicbilateral postural stability on the Biodex Stability System in olderadults. Med Sci Sports Exerc. 2004;36:530.

21. Eftekharsadat B, Babaei-Ghazani A, Mohammadzadeh M, et al. Effect of virtual reality-based balance training in multi plesclerosis. NeurolRes. 2015; 37:539-45.

22. Michikawa $T$, Nishiwaki $Y$, Takebayashi $T$, et al. One-legstanding test for elderly populations. J OrthopSci. 2009; 14:675-85.

23. Eser S, Saatli G, Eser E, et al. The Reliability andValidity of theTurkishVersion of the World HealthOrganizationQuality of Life Instrument-OlderAdultsModule (WHOQOL-Old). Turk Psikiyatri Derg. 2010; 21:37-48.

24. Kishimoto H, Hata J, Ninomiya T, et al. Mid life andlate-life hand grip strengthand risk of cause-specificdeath in a general Japanese population: the Hisayama Study. J Epidemiol Community Health. 2014; 68:663-8.

25. Bohannon RW, Peolsson A, Massy-Westropp N, et al. Reference valuesforadult grip strength measured with a Jamardy namometer: a descriptive meta-analysis. Physiotherapy. 2006; 92:11-15.

26. Evcik D, Kızılay B. Correlation of hand grip srengt hand disability in daily living activities in geriatricpatients. Turk Geriatri Derg. 2001;1:11-14.

27. Davis JW, Ross PD, Preston SD, et al. Strength, physicalactivity, and body massindex: relationship to performance-basedme asure sand activities of dailylivingamongolder Japan ese women in Hawaii. J Am Geriatr Soc. 1998; 46:274-9.

28. Stevens KN, Lang IA, Guralnik JM, et al. Epidemiology of balance and dizziness in a national population: findings from the English LongitudinalStudy of Ageing. Age Ageing. 2008; 37:300-305.

29. Sirola J, Rikkonen T, Kröger H, et al. Factorsrelatedto post menopausal muscle performance: a cross-sectionalpopulation-basedstudy. Eur J ApplPhysiol. 2004; 93:1027. 
30. Ashburn A, Hyndman D, Pickering R, et al. Predicting people with stroke at risk of falls. Age Ageing. 2008; 37:270-6.

31. Zulkaplı N, Saat NZ, Kamaral zaman S. Posturalcontrolin fluence on upper extremity functionamong children with cerebral palsy: A LiteratureReview. Jurnal SainsKesihatan Malaysia. 2016; 14:11-21.

32. Horak FB, Esselman P, Anderson ME, et al. The effects of movement velocity, massdisplaced, and taskcertainty on associated postural adjust mentsmade by normal and hemiplegic individuals. J Neurol Neurosurg Psychiatry. 1984; 47:1-9.

33. Telatar TG.,Özcebe H. Yaşlı nüfus ve yaşam kalitelerinin yükseltilmesi. Turkish Jornal of Geriatrics.2004; 7 : 162-5.

34. Park JE, Jang HJ, Seo KS. Quality of life, upper extremity functionand the effect of lym phedematreatment in breast can cerrelated lym phedema patients. Ann Rehabil Med. 2012; 36:240-7.

35.Gorter RR, Vos CG, Halmans J, et al. Evaluation of arm functionand quality of life after trimodality treatment for superior sulcus tumours. Interact CardiovascThoracSurg. 2013; 16:44-8. 